\title{
MUSEUS DO CENTRO HISTÓRICO DE BELÉM: REFLEXÕES SOBRE AMAZÔNIA-TERRITÓRIO NAS NARRATIVAS OFICIALIZADAS
}

Jessica Santos Silva

Instituto de Ciências da Arte; Universidade Federal do Pará; área de atuação em Museologia. E-mail: jessica.santo.silva.js@gmail.com.

Julie Castro de Sousa

Instituto de Ciências da Arte; Universidade Federal do Pará; área de atuação em Museologia. E-mail: castrojulie18@gmail.com

\section{RESUMO}

A atual Amazônia não é a mesma encontrada pelos colonizadores europeus, modificações aconteceram em seu território, seguindo uma lógica de exploração e dominação do espaço. Ciclos da exploração foram um dos que marcaram a região. Populações indígenas e negras sofreram duramente com todo este processo e atualmente enfrentam diversos obstáculos. Com estas questões em mente é preciso fazer uma análise da forma como os museus tratam sobre estas mudanças e como reforçam discursos que são fundamentados a partir do pensamento etnocêntrico ocidental.

PALAVRAS-CHAVE: Museus. Amazônia. Colonialismo.

\section{MUSEUMS OF THE BELÉM HISTORICAL CENTER: REFLECTIONS ON AMAZONIA- TERRITORY IN OFFICIALIZED NARRATIVES}

\begin{abstract}
The present Amazon is not the same as that found by European colonists, changes took place in their territory, following a logic of exploration and domination of space. Exploration cycles were one of those that marked the region. Indigenous and black populations have suffered hard from this whole process and currently face several obstacles. With these questions in mind, it is
\end{abstract}


necessary to analyze the way museums deal with these changes and how they reinforce discourses that are based on Western ethnocentric thinking.

KEYWORDS: Museums. Amazon. Colonialism.

\section{INTRODUÇÃO}

Desde o período colonial, o espaço que conhecemos hoje como Amazônia passou por várias modificações, tanto culturais, sociais e territoriais. Em todos estes momentos a Amazônia foi vista como um grande objeto de exploração, começando com a extração do Pau Brasil, passando pelas Drogas do Sertão e a exploração da borracha. Todos estes períodos marcaram bem as mudanças que ocorreram aqui. $\mathrm{O}$ primeiro momento com a chegada dos exploradores no território Amazônico, o grande atrativo do novo lugar encontrado de uma forma acidental, foi a paisagem considerada exótica que os europeus encontraram, além das populações indígenas, e neste momento existiu o desejo de dominar aquele lugar e as comunidades. Neste período, entra em cena as ordens religiosas que vieram para cá com o objetivo de "evangelizar" estas populações nativas. Uma delas foi à ordem jesuíta Companhia de Jesus, que com a missão de catequizar os índios a pedido da Coroa portuguesa, a ideia de evangelizar se caracteriza como uma forma de dominação, e estas atitudes também levaram os exploradores europeus a escravizar a população indígena, assim como a escravização da população negra.

E estas duas atividades geraram consequências que atualmente podem ser observadas na sociedade, como o descaso com as aldeias indígenas que ainda permanecem no país e a marginalização da população negra.

Após tanto tempo desde a primeira atividade de exploração, a Amazônia ainda é motivo de conflitos de vários países e de entidades dentro do Brasil, por conta de seus recursos. No período ditatorial que aconteceu no Brasil entre os anos de 1964 a 1985, a ocupação da Amazônia foi uma das propostas do então governo. Lançando campanhas que incentivaram a migração, principalmente da população nordestina a vir trabalhar na extração da borracha, que pode ser considerada o segundo ciclo de exploração das seringueiras, o primeiro então acontecido no século XVIII e começo do século XIV. Em A Batalha da Borracha: Propaganda Política e Imigração Nordestina Para a Amazônia Durante o Estado Novo de autoria de Isabel Guillen, se discute esta situação, assim como o termo "Soldados da Borracha" que foram estas pessoas mandadas para o meio da floresta, para lutarem a favor do 
crescimento econômico do país.

Dessa forma, o grande incentivo a "ocupação" da Amazônia foi efetivado no decorrer dos governos militares como modo de integrar o território e vincular ao movimento nacionalista das décadas de 60 e 70 como estratégia de consolidar a soberania e controle do território amazônico. Entretanto, desde o século XVI já existiam relatos da Amazônia como espaço "livre" e repleto de elementos inimagináveis, percorrer este território significava o desbravamento do misticismo devido ao pensamento e discurso etnocêntrico que considerava os europeus superiores às demais populações, uma vez que o campo científico e as artes nascem europeias e por isso, as narrativas de sociedades diferentes foram desvalorizadas e silenciadas.

O artigo intitulado "Em torno dos bumerangues: Outras Histórias de Mocambos na Amazônia Colonial" do autor Flávio Gomes, disserta sobre a resistência dos negros escravizados e os locais criados por eles como uma forma de resistir a opressão e a sua situação de subserviência. Na introdução, Gomes explica o que seria a metáfora da Hidra de Lerna, uma criatura da mitologia grega que cada vez que cortam uma de suas cabeças nascem outras duas no lugar, ele faz uma analogia dessa metáfora com o surgimento e resistências desses mocambos. Além disso, referencia as demais revoltas que aconteceram no Brasil.

Nesse sentido, esta leitura elucida a relação que foi criada entre negros e indígenas, que, de certa forma, dividiam o mesmo sentimento de luta pela sua liberdade, lembrando que com a chegada dos exploradores forçaram as comunidades indígenas ao trabalho escravo, como já foi citado este monopólio de mão de obra indígena foi motivo de disputa entre colonos e jesuítas. E uma das maneiras de resistência por parte da população negra escravizada era as relações criadas entre os comerciantes e indígenas, pois como ambos conheciam a região, havia trocas de informações referente à geografia do lugar, além das notícias de revoltas que aconteciam na Europa, e como cada situação influenciava a outra. Também precisa ser destacado que assim como os indígenas, os negros não eram vistos como indivíduos e isto gerou consequências que reverberam na sociedade brasileira.

\section{DESENVOLVIMENTO}

E todo este discurso de colonialismo, ainda é representado nos museus de Belém, como o Museu do Encontro, que o próprio nome já diz, marcaria um encontro entre os europeus e indígenas, mas esta ocasião não pode ser denominada de encontro, pois houve confronto entre 
as populações, o que dizimou centenas de aldeias indígenas que hoje só conhecemos traços de suas culturas através do museu e pelos nomes das ruas, como Rua dos Tupinambás e Tamoios. Refletindo estas "homenagens" seriam uma forma de se redimir pelo que ocorreu a estas populações. Ainda sobre o Museu do Encontro, em um dos textos de apoio da exposição, é comentado sobre as comunidades indígenas e como o número caiu desde a chegada dos exploradores, apesar do texto fazer referência aos conflitos com os portugueses e a escravização dos povos, é colocado como primeira causa da diminuição destas populações as doenças, que foram trazidas pelos europeus. Mas as várias guerras e invasões que ocorreram nas aldeias indígenas precisam ser mais bem destacadas. Em Belém, se é observado muita dificuldade em destacar este fato, até no aprendizado do ensino básico, apenas se fala do estereótipo do indígena, imagem também criada pelos europeus. A própria Cabanagem, que foi uma revolução protagonizada por indígenas, negros e seus descendentes, é pouco estudada nas escolas, o que existe atualmente para lembrar este fato, é uma sala expográfica no Museu do Estado (MEP) e um monumento criado pelo arquiteto Oscar Niemeyer, que hoje se encontra abandonado pelo poder público.

O Museu de Arte Sacra, é outro museu que também não elucida questões indígenas, mesmo constando informações nas placas informativas de algumas obras. Estas peças foram produzidas durante as oficinas do Colégio Jesuíta, que se tornou o Museu de Arte Sacra, assim como no Museu do Encontro, é importante destacar. Outro museu que não expõe diretamente a questão indígena é o Museu do Estado do Pará (MEP), este espaço representa a Belle Époque, todo o luxo deste período que Belém passou, a partir da exploração da borracha. No museu existe apenas uma sala sobre a revolta cabana, precisa ser ressaltado que o Palácio Antônio Lemos, que abriga o museu, foi um dos lugares que marcaram a revolta, por ter sido o Palácio dos Governadores. Além disso, a grande obra do museu é uma pintura do artista Antônio Parreira, chamada de A Conquista do Amazonas, onde a mesma tem uma sala exclusiva no espaço. Percebe-se que o nome da obra faz menção da chegada dos portugueses, como se estes tivessem conquistado a Amazônia, pensamento este que ainda permanece. $\mathrm{O}$ que pode ser observado também é que nenhum destes museus fazem referência a população negra, que também foi escravizada, é como se não tivessem dados suficientes que comprovem a existência de pessoas negras, esse grupo é realmente esquecido pelos principais museus do Centro Histórico de Belém.

Nesse sentido, refletir sobre narrativas institucionalizadas é uma dinâmica fundamental 
na teoria e na prática, a materialidade e a imaterialidade são equivalentes, e inseridas em contextos específicos possibilitam o preenchimento de lacunas registradas intencionalmente ou não. Para tanto, a Museologia enquanto campo disciplinar propõe discussões acerca das histórias oficializadas, é preciso repensar sobre quais instrumentos de análise estão sendo utilizados para rememorar descrições feitas a partir de relatos oriundos do Estado.

Neste ângulo, referenciais museológicos reverberam o embasamento fundamental para percorrer a revisita de construções de memórias que são administradas em razão de vertentes políticas, em um jogo interminável de poder oligárquico. É necessário ponderar que a Museologia registra uma metodologia interessante para apontar os recortes de memórias, a musealização, é um processo que ao passo que dialoga com outras perspectivas delimita um espaço da realidade e inclina a concepção de perceber os enfoques anteriores e as mudanças conceituais que ocorrem durante o tempo que valores simbólicos e representativos para identidades locais são atribuídos. Por isso, é possível pensar a partir do chamado 'olhar museológico' (CHAGAS, 1994) sobre as narrativas propagadas com relação à região amazônica implica afirmar que questionar signos culturais estabelecidos são configurados como verdades potenciais, ou seja, passíveis de reivindicações individuais ou coletivas que podem acontecer constantemente.

De acordo com a teórica Diana Lima, a Museologia está direcionada de forma íntima com o museu, no entanto, durante um período temporal longo esteve concentrada apenas ao campo intelectual e aos espaços museológicos físicos. Em contrapartida, o campo científico museológico permitiu a partir de impulsos constantes de pesquisas e discussões a necessidade de visualização dos espaços sociais, uma vez que, as produções científicas são manifestos políticos.

À proporção que é imprescindível analisar que a existência de uma proposta museológica que considera a Museologia para além das instituições museológicas licencia pensar acerca de lugares de memória, segundo Pierre Norá, que são registros de desenvolvimento que partem da compreensão da não existência de memórias involuntárias, isto significa que para a memória ser mantida à vista, é preciso a administração de agentes externos que proporcionem a visibilização.

Desse modo, é superficial que a Museologia brasileira não movimente debates acerca de cenários atuais, pois é imprescindível discutir sobre questões que envolvem estratégias de resistência de populações nativas, populações africanas que estão dentro de uma conjuntura 
forçada de viagem e demais populações que foram incentivadas ao processo de imigração para o Brasil.

Diante disso, é oportuno compreender que os museus brasileiros não estão vinculados às diferentes possibilidades de narrativas, são instituiçõos que representam políticas culturais manipuladas por conceitos elitistas. Portanto, produzir epistemologias e alinhar essas produções ao campo prático colapsa as estruturas vigentes de poder uma vez que dialogar sobre pautas cotidianas precisa ser um dos propósitos da pesquisa brasileira, é indispensável que os discursos coloniais sejam enfrentados a fim de forçar agências políticas ao desconforto. A Museologia e os Museus precisam ocasionar incômodos, é primordial que espaços sejam escancarados, narrativas sejam repensadas e recontadas outros relatos ao longo da história oficializada.

\section{CONSIDERAÇÕES FINAIS}

Diante dos pontos levantados, a Amazônia ainda continua sendo vista como um vasto território de exploração, que precisa ser ocupado e dominado, assim como ocorrido no momento da chegada dos exploradores. As populações que lutavam por direitos de existência e memórias no período, ainda hoje se encontram entrepostas em confrontos simbólicos e físicos de resistência, além disso, os museus que poderiam ser locais de possíveis visibilidades e narrativas que contemplem diversos grupos étnicos não cumprem este papel, ainda reforçam estereótipos e discursos de instituições colonialistas.

\section{REFERÊNCIAS BIBLIOGRÁFICAS}

CHAGAS, Mario de Souza. No Museu com a turma do Charlie Brown Jr. 1994.

CANCLINI, Néstor A encenação do popular In.: Culturas híbridas São Paulo: Edusp, 2003.

COSTA, Deyseane Ferraz da. Patrimônio e história: Os Jesuítas na Amazônial organizadores Deyseane Ferraz da Costa, Karl Heinz Arena Belém: Paka - Tatu, 2014. dos bumerangues: outras histórias de mocambos na Amazônia colonial. O povo Negro, revista USP, São Paulo (28): 40 - 55. Dezembro / Fevereiro 95/96.

GUILLEN, Isabel Cristina Martins. A Batalha da Borracha: Propaganda Política e Imigração Nordestina Para a Amazônia Durante o Estado Novo.

LIMA, Diana Farjalla Correia. Museologia-Museu e Patrimônio, Patrimonialização e Musealização: ambiência de comunhão. Boletim do Museu Paraense Emílio Goeldi. 
Ciências Humanas, v.1, n. 1, p. 31-50, 2012.

LIMA, Diana Farjalla Correia. Musealização: um juízo/uma atitude do campo da Museologia integrando Musealidade e Museália. Ciência da Informação, v. 42 , n. 3. 2015.

NORA, Pierre et al. Entre memória e história: a problemática dos lugares.
Projeto História: Revista do Programa de Estudos Pós-graduados de História, v. $10,1993$.

SANTOS, Myrian Sepúlveda dos. Museus Brasileiros e Política Cultural. In: Revista Brasileira de Ciências Sociais. pp. 53-72. Vol. $19 \mathrm{n}^{\mathrm{o}}$. 55 junho/2004.

SILVA, J. S., SOUZA, J. C. Museus do Centro Histórico de Belém: Reflexões sobre AmazôniaTerritório nas Narrativas Oficializadas. Complexitas - Rev. Fil. Tem. Belém, v. 4, n. 2, p. 107-113, jul./dec. 2019. Disponível em: http://www.periodicos.ufpa.br/index.php/complexitas/article/view/8055>. Acesso em: 30 de janeiro de 2020. 